Article

\title{
A Stakeholder Analysis for a Water-Energy-Food Nexus Evaluation in an Atlantic Forest Area: Implications for an Integrated Assessment and a Participatory Approach
}

\author{
Giacomo Melloni ${ }^{1}$, Ana Paula Dias Turetta ${ }^{2,3}$ (D), Michelle Bonatti ${ }^{3,4, *}$ and Stefan Sieber ${ }^{3,4}$ \\ 1 Department of Economics and Management, University of Florence, Piazza San Marco, 4, 50121 Florence, \\ Italy; gmelloni95@gmail.com \\ 2 Brazilian Agricultural Research Corporation (EMBRAPA Soils), Rio de Janeiro, R.J., \\ Program of Territorial Development and Public Policy, Federal Rural University of Rio de Janeiro, \\ Seropedica 23890-000, Brazil; ana.turetta@embrapa.br \\ 3 Leibniz Centre for Agricultural Landscape Research (ZALF), Eberswalder Straße 84, 15374 Müncheberg, \\ Germany; stefan.sieber@zalf.de \\ 4 Department of Agricultural Economics, Faculty of Life Sciences Thaer-Institute, \\ Humboldt-Universität zu Berlin, Unter den Linden 6, 10099 Berlin, Germany \\ * Correspondence: michelle.bonatti@zalf.de
}

Received: 22 May 2020; Accepted: 28 June 2020; Published: 13 July 2020

\begin{abstract}
A water-energy-food (WEF) nexus assessment supports natural resource management by providing an integrated framework for evaluation and decision-making. The participation of a wide range of stakeholders is essential for achieving environmental, economic, and social sustainability in this framework. This analysis supports the decision-making process of the nexus assessment by facilitating dialogue between stakeholders in order to achieve long term efficiencies, especially in rural landscapes where most of the services connected to WEF securities are provided. We identify the most relevant stakeholders operating in the connection between agricultural practices and the WEF nexus to stimulate their engagement in the nexus governance. The study area was the Atlantic Forest Reserve of Ribeirão das Lajes, Brazil. A stakeholder analysis, generating qualitative data using snowball sampling interviews was applied and, after the identification of stakeholders, an analytical categorization disclosing potential conflicts among them was performed. We obtained a pool of stakeholders from different organizational types, including a large number of public entities at local and state levels. The main threat to the development of the project is considered to be the lack of communication between the parties. We note that the prior identification of this group of stakeholders facilitates this communication, enhancing social representation in the area. Outcomes of this study demonstrate the relevance of stakeholder analysis in nexus governance for integrated natural resource management.
\end{abstract}

Keywords: natural resource management; nexus approach; sustainability; stakeholder analysis; participatory methodology

\section{Introduction}

Natural resource management is a multifaceted endeavor, as is the concept of sustainability. Active and continuous consultation between experts and stakeholders is fundamental for two main reasons. First, on the part of natural resources, it is necessary to highlight the interlinkages that exist in their use and production. The Water-Energy-Food nexus aims at defining the risks and 
opportunities that comprise a given scenario and the possible solutions that may apply to it. It is especially important for the planning of rural landscapes, where most of the areas (water springs, forest fragments, agricultural fields, among others) that provide the vital ecosystem functions are located. Experts from different backgrounds must work together to build a common understanding of the complexity of each distinct system, defining a portfolio of effective policy responses or direct action initiatives [1,2]. The evaluation then proceeds using a transdisciplinary research design based on high coordination between experts through co-creation of knowledge, cross-validation, and case-specific adaptation [3].

Secondly, when dealing with environmental projects aimed at the preservation of landscapes or natural resources, it is necessary to draw a line between the use and protection of certain limited resources. However, preferences about where to draw this line may vary among decision-makers and beneficiaries of the resources, who may have discordant views [4].

For a project to be sustainable from the economic, social, and environmental point of view, it is necessary that both of these dialogical evaluation processes work effectively and that they are then integrated with each other. Thus, a process of this kind requires a good and common understanding of both the physical and the institutional scenarios, determined by the stakeholders and their interests. In this framework we define stakeholders not only to include those individuals who can affect the outcome of the project, but also those who may be affected [5]. Without this understanding, a project may fail, for example, in representing the needs of marginalized parts of society or the needs of a local community. Engaging these actors in the governance process relating to public goods may result in their empowerment, enhancing the democratic process through the institutions involved [6,7].

We propose stakeholder identification and categorization for a nexus assessment of the Ribeirão das Lajes reservoir, located in the hydrographic region of Guandu, in the Brazilian state of Rio de Janeiro, whose resources are threatened by anthropic action and climate change. The nexus assessment project is named Projeto Nexus and aims to identify the impact of agricultural practices in the water-energy-food (WEF) nexus. The wellbeing of the population of the state, as well as of the local economy, is strictly reliant on the water of the basin and, therefore, on its long-term preservation. Moreover, the area is located in the Atlantic Forest biome, one of the hot spots of biodiversity in Brazil. This analysis addresses the research questions: Who are the stakeholders involved in food, energy, and water governance in the rural landscapes of Rio de Janeiro's Atlantic Forest? What type of organization are they and what are the implications for integrated nexus governance? The present work is designed to prevent science-to-policy gaps [8] between experts leading the evaluation process and the decision-makers, as well as gaps between the decision-makers and the users of the resources of the reservoir of Ribeirão das Lajes, thus fostering public participation [9].

Brazil represents an exemplary testing ground for the challenges that the nexus is set to overcome, not only since it is one of the regions that will be badly affected by climate change [10], but also because its economy is intensely related to global economic trends, being highly reliant on its exports of farming and agricultural products, as well as of energy commodities [11]. The use and production of these resources is thus strongly interconnected. These problems are even more urgent in the Atlantic forest biome, as three-quarters of Brazil's population live in this biome putting its integrity at severe risk. A better understanding by, and involvement of, the federal, state and municipal institutional decision-makers could result in the implementation of science-informed policy-making based on the nexus.

\subsection{The Water-Energy-Food Nexus Approach}

The nexus approach was developed to face the challenges coming from the rising demand for food, water, and energy, which, due to global population growth and climate change, are increasingly scarce, facing ever increasing demand [2]. Globally, 90\% of water depletion is caused by agricultural food production and energy generation [8]. Policymakers need tools that incorporate the interlinkages between water, energy, and food. Nexus assessment offers a research framework that can be used for 
this purpose: by analyzing synergies and trade-offs, it seeks to break down the different concurring factors in a uniform structure to describe a complex reality.

In the 2010s, scholars made large use of the nexus in academic research [12,13] in response to what was considered overly sector-specific responsiveness to environmental and resource management [14-16]. The supporters of the nexus approach advocate that an integrated assessment of the issues that affect natural resources will result in a more sustainable response [15]. It is also noted that the resulting better allocation of resources in a specific region will result in more effective protection of the poor, whose subsistence is often tightly linked to environmental integrity [17].

However, while it is developing quickly, many also point out the multi-sectoral challenges that arise from this approach, rooted in the complex reality of institutions that often operate in 'silos' addressing resource management individually in each respective regional context $[15,18,19]$. Subsequently, the commitment to developing a robust and integrated scientific response is not sufficient to develop an efficient policy response when this is not supported by efficient coordination and equal understanding between decision-makers $[11,15,20]$. To understand the complex system of linkages among the institutions that use and control these sectors in each geographical context, the nexus approach calls for continuous stakeholder dialogue [2] between researchers and stakeholders [8]. To facilitate this dialog, some authors are developing methodologies that engage stakeholders in nexus governance and decision-making, including semi-structured interviews [21] and workshops [19] involving academics, policy-makers, or private individuals.

The stakeholder analysis has appeared as a strong approach as demonstrated by White et al. [13], who assesses the understanding of the nexus among the stakeholders in Phoenix, Arizona, to enhance nexus governance through focus groups and interviews. In another study on the project Central Asia Nexus Dialogue, a stakeholder analysis was carried out to improve inter-sectoral cooperation in the WEF nexus as an aspect of communication strategy using working groups, national consultation, and meetings [22].

With this study, we present stakeholder analysis as a functional tool that supports stakeholder dialogue in the decision-making process of nexus assessment. We test the snowball sampling methodology to check multi-level stakeholder involvement. We seek to verify the ability of this method to define the stakeholder scenario regarding the impact of agricultural practices and their impacts on nexus assessment in Ribeirão das Lajes, which is the novel aspect of our findings. Snowball sampling has been proven to be an effective sampling technique to include hard-to-reach hidden population subgroups [23], especially when dealing with diverse communities [24]. In the case of the present analysis, the diversity of the stakeholders is reflected in the diverse water-energy-food institutional environment and representative institutions and by the large share of beneficiaries that may be affected by a change in the use of the resources of the area. We have then operated stakeholder categorization accordingly in the attempt to highlight the nature of the organizational structure (private or public) and the scale on which they operate. In our approach we focused on overcoming two challenges to the nexus. These are: (i) including a wide range of diverse stakeholders in order to increase the representativeness of the affected population and to foster the co-creation of knowledge from diverse backgrounds involved in the decision making [1,2,8]; and (ii) delineating the existing governance framework of public and private stakeholders operating at different scales (local, state, or national) in the region. The lack of integration among private and public sector, or the public sector operating at different scales or in different nexus areas, may result in a discontinuous flow of scientific knowledge and understanding of the nexus, harming the decision-making process and effective integrated policy-implementation for land-use management $[11,15,19,20]$.

\subsection{Participative Approaches and Stakeholder Analysis in Environmental and Conservation Projects}

Resource managers have often preferred to avoid undergoing participatory models that include a large number of stakeholders with different backgrounds [25]. This is because it was believed that different interests and views would significantly slow down the decision-making process [4] and also 
because stakeholder engagement requires more money and effort [19]. As a result, decision-makers opted for what is conventionally called a "theory-driven approach" that relies mostly on past research and examples [26], or 'silo' approaches carried out alone by specialized institutions and agencies [27].

Nonetheless, it is recognized that a participatory modeling approach requires wide stakeholder participation, thus representing a more effective process to deal with the use of natural resources [28]. The linkages that exist between the managers and the beneficiaries of a certain ecological system are an integral component of such a system, being determinant to its evolution [29].

It is possible to sum up the functions that a participative stakeholder dialogue serves in an evaluation project in three ways $[30,31]$. First, it serves a normative function; by focusing on the process of inclusion and social participation, it stimulates a sense of ownership and responsibility in the population regarding public goods. Furthermore, it grows confidence in the democratic representative power of institutions by adding transparency to the governance process [32]. Secondly, it has a substantive function by allowing an enriched understanding of the situation that stimulates cross-validation and co-creation of knowledge, thus increasing the legitimacy of a model. This is particularly evident throughout nexus assessment, which discloses the multidimensional endeavor via which the use and production of resources are linked, thus demonstrating the need for diverse knowledge in the evaluation process [1]. Moreover, considering the opinion of actors that live or work in close contact with the resources at stake (the "wisdom of crowds") adds knowledge about the peculiarities of the problem, helping to tackle it in a better-targeted way [33]. Thirdly, it has an instrumental function since cooperation between players highlights diverging interests that may potentially harm the success of the project, thus stimulating the creation of a common goal to better address collective action and decision making [32]. Furthermore, within the framework of nexus assessment, it unveils how the administration of WEF sectors is institutionally linked across local and national scales [13].

In this light, the present stakeholder analysis moves to build a common understanding of the urgencies among the stakeholders included, starting from a group of experts and institutional stakeholders who are more closely involved in the project or the region considered. This already diverse group comprises individuals from the public and private spheres and with differing interests in the project, be it economic, political, or social. We aim at drawing attention to the level of involvement of each player and to nourish a deeper understanding of the group of individuals who are not included, who could either cooperate with or work against the future development of the project. We adopt the definition of stakeholder based on Freeman's seminal work [5], incorporating not only the people who may affect the project but also those who will be affected by the intervention.

\section{Materials and Methods}

\subsection{The Nexus Assessment and the Region of Ribeirão das Lajes}

The nexus assessment carried out in Projeto Nexus aims at identifying the best conservation agricultural practices to ensure water, energy, and food security in the Ribeirão das Lajes reservoir, located in the Hydrographic Region of Guandu, in the Brazilian state of Rio de Janeiro (Figure 1). The area is crucially relevant for the economic and social wellbeing of the state of Rio de Janeiro: not only is it responsible for supplying water to $80 \%$ of the population of the greater area of the state (around 9 million people), but it is also employed in local agriculture and produces $25 \%$ of the electricity consumed [34]. The resources of the reservoir are continuously put at risk due to the region's fragile ecosystem, which has undergone significant transformations over the years and faces risks derived from climate change. Soil degradation threatens the availability of water, while pollution of the affluent rivers of the basin repeatedly causes contamination problems that affect the population of the State, thus putting the management of the region in the media spotlight (https://www.ecodebate.com.br/2020/ 02/21/agua-potavel-a-insustentavel-situacao-do-saneamento-no-brasil-2/). Furthermore, the reservoir is located in the biome of the Atlantic forest, which, facing heavy deforestation and fragmentation, 
is steadily shrinking, with the majority of remnant areas lacking legal protection [35]. The fragile ecosystem of Ribeirão das Lajes is indicative of the vulnerability of the water supply system that the country is facing as a consequence of climate change. In 2014 a severe drought led the biggest dams of Brazil operating at only 16.1\% of their capacity [36], causing extreme shocks in hydropower consumption and lack of water for the population and agriculture, calling for more attention on the interlinkages between these resources [37].

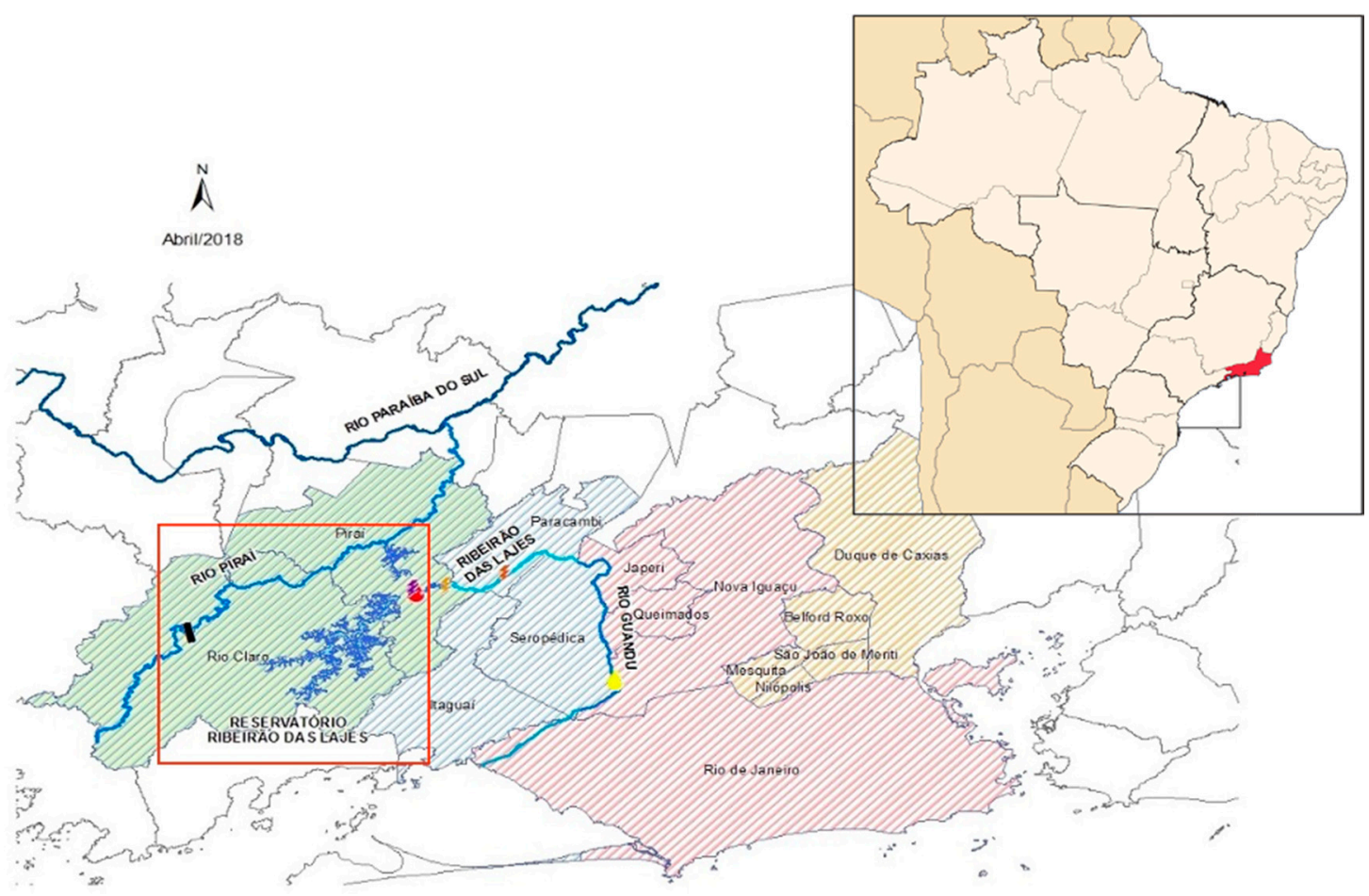

Figure 1. Basin of Guandu river's hydrographic region.

The construction of the dam started in 1905 with the primary intent of generating electric energy for Rio de Janeiro, then the capital of Brazil, and was promoted by Light, a Canadian company that still has property claims in the area [38].

Vaz [38] and Serqueira [39] argue that, throughout the historical development of the reservoir, the binding necessities triggered by the industrialization of Rio de Janeiro and its rapid population growth have often put pressure on the decision-making process regarding its implementation and have resulted in irreversible damages to the environment, people, animals, and materials.

Currently, Light group, in addition to being the largest landowner in the State of Rio de Janeiro, is the major supplier of energy to the population, with a capacity of $855 \mathrm{MW}$. Today the group declares through its public channels (http://www.light.com.br/grupo-light/Empresas-do-Grupo/light-energia.aspx) its commitment to the sustainable development of its properties and, therefore, is interested in pursuing projects in this direction.

\subsection{Methodology}

Following the definitions of Reed et al. [9], our stakeholder analysis is driven by both a normative and an instrumental rationale (Figure 2). The instrumental rationale seeks to stimulate the co-creation and cross-validation of knowledge in a cooperative process for the implementation of the project. By drawing from a pool of already known stakeholders, we ask them to disclose information regarding their interests and their opinion on covert stakeholders who are otherwise neglected, in an attempt to generate the co-production of knowledge that will be used to encourage the decision-making process in WEF governance. The normative driver of our analysis is provided by the effort to include a larger 
range of societal needs and preferences into the evaluation process, trying to identify the best entities that can represent the nine million beneficiaries demanding water, energy and food security.

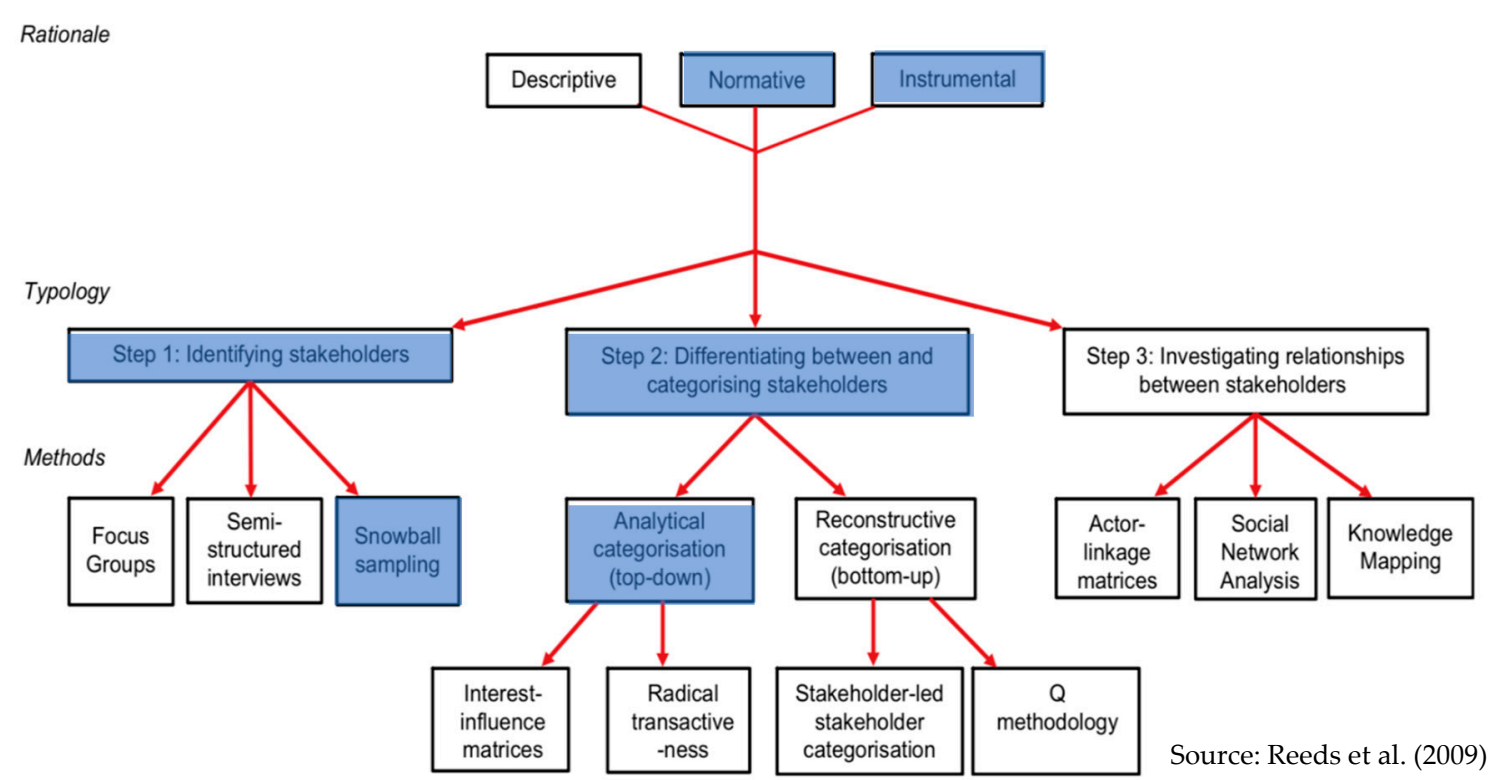

Figure 2. Schematic representation of the stakeholder analysis rationale, typology and methods according to Reeds et al. (2009) [9]. The procedures adopted in this research are highlighted in blue.

With the present analysis, we aim to fulfill the identification and categorization of the stakeholders and unveil possible conflicts among them in our attempt to answer our research question. We want to disclose stakeholders who may have been neglected to both inform them about the issues being tackled in the nexus assessment and to include them in the decision-making process. By doing so, we can express our results in terms of the implications of a stakeholder analysis for an integrated nexus assessment of natural resource governance.

\subsubsection{Framework for Participatory Impact Assessment}

Albeit not strictly relevant for the purpose of this research, the present stakeholder analysis will contribute also to the theoretical framework of the evaluation process of Projeto Nexus, the Framework for Participatory Impact Assessment (FoPIA). Following König et al. [40], the FoPIA methodology, a participatory methodology designed to assess the impact of land-use policies and investments on regional sustainability [40-42], was used as a basis for the participatory engagement in the project. We applied its three main stages: the first stage is to develop the local scenario by describing the physical aspects as well as current public policies that may apply and the socio-economic situation of the area; in the second phase, the effect of a set of possible agricultural practices and their effectiveness is evaluated with regards to the state of water, food, and energy security in the area; in the third stage, the results are used to build up impact scenarios and validate them with the stakeholders. A stakeholders analysis serves the purposes of FoPIA by providing qualitative data that outline the wide number of actors who live and operate with the resources at stake, to inform them of the risks and to debate the best solutions that have been identified based on the needs of the population and of the local economy. Large and influential stakeholders are also identified within the framework of the FoPIA as they may contribute to the decision-making process with their knowledge or, instead, obstruct its implementation. 


\subsubsection{Selection of Participants}

The first step of this research employs a snowball sampling strategy conducted among a number of informants from different organizations either partnering in or assisting with the evaluation of the nexus assessment in Ribeirão das Lajes. This base of informants was selected for its expertise and understanding of the WEF nexus and its solid knowledge of the historical development of the region.

Through an online survey, we gathered opinions from 10 respondents across four different organizations that represent expertise in all the three nexus sectors. In order to include a broad range of different interests, these organizations pertain to different environmental governance sectors, including the public, private, and nonprofit arenas.

The informants pointed out a set of organizations, individuals, and associations that they defined as crucial in the decision-making process and that should, therefore, be included-if they were not already part of the nexus assessment group.

\subsubsection{Data Collection and Analysis Procedure}

We created an online survey using Google Forms and shared it via email with partners of the nexus assessment group of Ribeirão das Lajes. The decision to use an online survey was due to the fact that the interviewers and the interviewees were in different locations at the time of the survey. The survey was structured in four questions that aimed to qualitatively identify: (i) the main issue to be tackled in the reservoir, thus highlighting their interests; (ii) the urgency of an intervention in the area, thus highlighting their level of concern; (iii) their opinion of the stakeholders who play a crucial role in the implementation of the project who either have high influence in the decision-making process or who could have influence if they were involved; and, finally, (iv) their opinion of the stakeholders who may undermine the development of the project, who are either already included or who should be included to resolve covert conflicts.

With the results obtained, we seek to obtain a list of the stakeholders who need to be involved. We then use this list to identify them by the frequency with which a certain stakeholder is mentioned through snowball sampling interviews. Next, we operate a categorization of these stakeholders. This is an analytical top-down categorization [43]. The analytical methodology assumes that the researchers define the categories according to the main objectives of the project, in order to have a clear vision about which stakeholders should be engaged for each particular aspect of the project. Since the assessment comprises the three dimensions of water, electricity, and food security, the categories used are the main area of interest for each stakeholder in terms of the WEF nexus, the governance sector (i.e., private, public, nonprofit), and the level on which they are active (basin, local, state, national, or international). This attempts to unveil the possible dynamics of cooperation, or threat, between the public and private sectors throughout the implementation of the project. This categorization is implemented as a continuous process by the stakeholders themselves through a reconstructive bottom-up categorization in the next steps of the assessment.

\section{Results and Discussion}

\subsection{Definition of the Issue and Stakeholder Framework}

In the first phase, participants were asked to highlight the main issues that affect the area under investigation, regarding the impact of agricultural practices in the WEF nexus. Responses show the different areas of interest that will define the boundaries of the stakeholder identification process, thus narrowing the selection to groups of experts or entities living or working closely with these factors. The respondents had the possibility to choose more than one option. In this regard, soil degradation was indicated by all informants as one of the main threats to be tackled, while water pollution was chosen by $50 \%$. Additionally, water availability and biodiversity were regularly mentioned by, respectively, $40 \%$ and $30 \%$ of the interviewees. Other existing issues, like the low touristic activity in the area, floods, and wildfires were not indicated as crucial for the Ribeiro das Lajes nexus assessment in this context. 


\subsubsection{Identification of the Stakeholders}

The identification process follows the direct result of the snowball sampling interviews. The list of all the organizations quoted gives an indication of the most widely identified stakeholders and is reported in Table 1.

Table 1. Frequency of stakeholders mentioned by different informants. The columns anonymously indicate the answers of the informants.

\begin{tabular}{|c|c|c|c|c|c|c|c|c|c|c|c|}
\hline Mentioned Stakeholder & & & & & for & ant & & & & & Total \\
\hline Light & - & & - & - & & & $\bullet$ & - & & 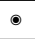 & 6 \\
\hline Cedae (State Company for Water and Sewage) & - & & - & & & 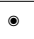 & - & - & & - & 6 \\
\hline Emater-Rj (Technical Assistance and Rural Extension RJ State Company) & $\odot$ & & & & ○ & & & & & & 2 \\
\hline Secretary of State for Agriculture, Livestock, Fishing and Supply (RJ) & $\odot$ & - & & & & & & & & $\odot$ & 3 \\
\hline Local Municipalities (generic) & - & - & - & & - & & & - & $\circ$ & 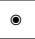 & 7 \\
\hline - City of Angra dos Reis & - & & & & & & & & & & 1 \\
\hline - City of Piraí & & - & & & & & & - & & - & 3 \\
\hline - City of Rio Claro & & - & & & & & & $\odot$ & $\bullet$ & 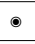 & 4 \\
\hline Health Protection Division of Piraí & - & & & & & & & & & & 1 \\
\hline Health Protection Division of Rio Claro & - & & & & & & & & & & 1 \\
\hline Local companies & - & & & & ० & - & & & 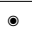 & & 4 \\
\hline Ambev & - & & & & & & & & & & 1 \\
\hline Nestlé & 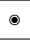 & & & & & & & & & & 1 \\
\hline Incra (National Institute for Colonization and Agrarian Reform) & 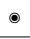 & & & & $\circ$ & $\bullet$ & & & & & 3 \\
\hline Sebrae- $\mathrm{Rj}$ & - & & & & & & & & & & 1 \\
\hline Senar-Rj (National Rural Learning Service) & - & & & & & & & & & & 1 \\
\hline Pesagro-Rio (Agricultural Research Company of the State of Rio de Janeiro) & - & & & & & & & & & & 1 \\
\hline Fiperj (State Fisheries Institute Foundation) & - & & & & & & & & & & 1 \\
\hline Saf/Mapa (Secretary of State for Family Agriculture and Cooperativism RJ) & $\bullet$ & & & & & & $\circ$ & & & & 2 \\
\hline Secretaria da agricoltura e do meio ambiente Rio Claro & & & & & & & - & & & & 1 \\
\hline Municipal Department for Agriculture (Piraí) & & & & & & & - & & & & 1 \\
\hline Municipal Department for the Environment (Piraí) & & & & & & & $\bullet$ & & & & 1 \\
\hline Secretary of State for the Environment and Sustainability (RJ) & & & & & & - & & $\circ$ & & & 3 \\
\hline Secretary of State for Social Development (RJ) & $\bullet$ & & & & & $\bullet$ & & & & & 2 \\
\hline Firjan & & & & & & & & $\circ$ & & & 1 \\
\hline Sicoob & $\odot$ & & & & & & & & & & 1 \\
\hline Banco do Brasil & - & & & & & & & & & & 1 \\
\hline Comite Guandu & & & & & & $\odot$ & - & $\circ$ & 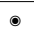 & - & 5 \\
\hline Inea (State Institute for the Environment) & & & & $\circ$ & & & & - & & - & 3 \\
\hline Epe (Energy Research Company) & & & & & & & - & & & & 1 \\
\hline Ceivap (Committee for Integration of the Paraíba do Sul River Basin) & & & & $\bullet$ & & & & & & & 1 \\
\hline Conservation International & & & & & & & & $\circ$ & & & 1 \\
\hline
\end{tabular}

It is possible to observe that there is a large number of public entities at all levels (local, federal or national) and a smaller number of private or non-profit entities. Out of the 32 mentioned entities, only a few are identified several times, suggesting that there is a limited group of stakeholders commonly recognized as being closely linked with the reservoir or with the nexus sectors in the area. On the other hand, several entities are mentioned only once, suggesting that their presence in the debate should be agreed upon among stakeholders.

The most recognized entities were Light, the company that owns property rights in the region and that, as mentioned earlier, has been the main decision-maker for over a century. Different governmental organizations represented the other most recognized entities, including the State Company for Water and Sewage (CEDAE), the State Institute for the Environment (INEA), the State Secretary for Agriculture (SEAPPA), and, lastly, the Committee for the Guandu Hydrographic Region. Furthermore, a large interest was shown in local municipalities, showing their need to be involved and their role in bringing the project closer to the local population. The municipalities of Rio Claro and Piraí, where the reservoir is located, were the most commonly identified, but there were several references to generic 
local municipalities needing to participate, thus widening this choice through further consultation, since the municipalities fully supplied by the resources of the reservoir include Itaguaí, Seropédica, Paracambi, and, partially, Japeri, Queimados, Nova Iguaçu, and the city of Rio de Janeiro. The other private entities that received attention included the private companies and rural producers in the area; however, these were named generically, thus indicating a need for further discussion before selecting a representative for this category.

\subsubsection{Stakeholder Categorization}

The stakeholders were classified and divided into categories by organization type, the level at which they operate (basin, local, state, national, international), and the main nexus sector interest (Water, Energy, Food). The results are shown in Table 2. This categorization discloses the main area of interest for each stakeholder for the different nexus elements, and the organization type. With this categorization we seek, on the one hand, to differentiate working skills and knowledge to better highlight each stakeholder's potential contribution to deliver the best sustainability-related outcome and, on the other hand, to highlight how much each organizational type represents the expertise and interest of each nexus sector. This categorization gives us a perception of the diversity of the stakeholders' environment to highlight sectoral division and different scales of operation. As Mercure et al. [11] highlight, the lack of coordination of the actors at different scales of governance and in different sectors may prejudice the implementation of effective policy in the interlinked nexus dimensions.

Table 2. List of stakeholders by Nexus sector of interest, type of organization and level of activity.

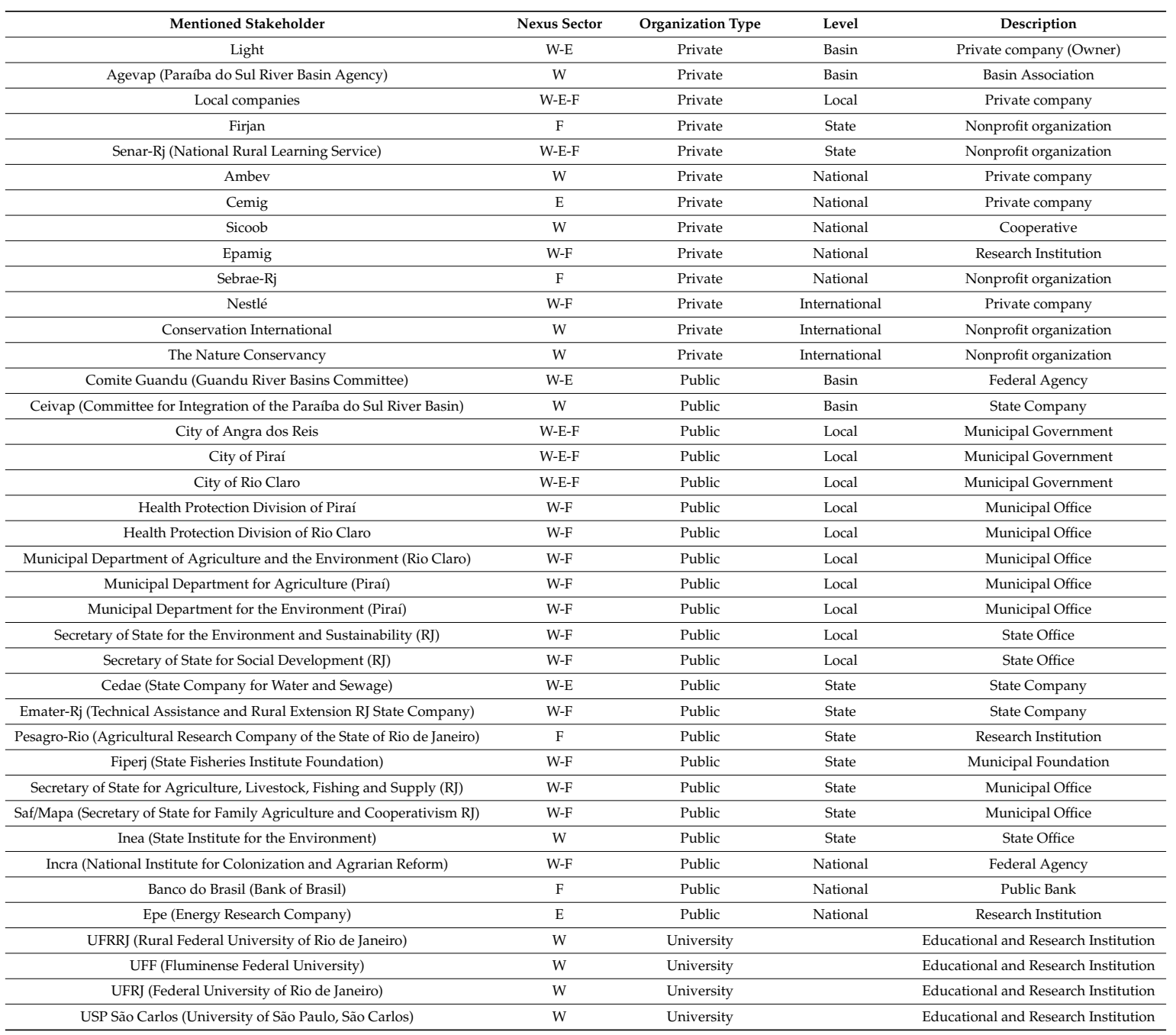


Responses gathered through the questionnaire from the partner organizations of the nexus assessment in Ribeirão das Lajes resulted in a list of 39 stakeholders of different backgrounds and different areas of interest. More than half of these are public entities (22, plus four public universities), and, out of the 13 private stakeholders, five are nonprofit organizations with environmental or educational purposes. Figure 3 summarizes the shares of stakeholder by organization type.

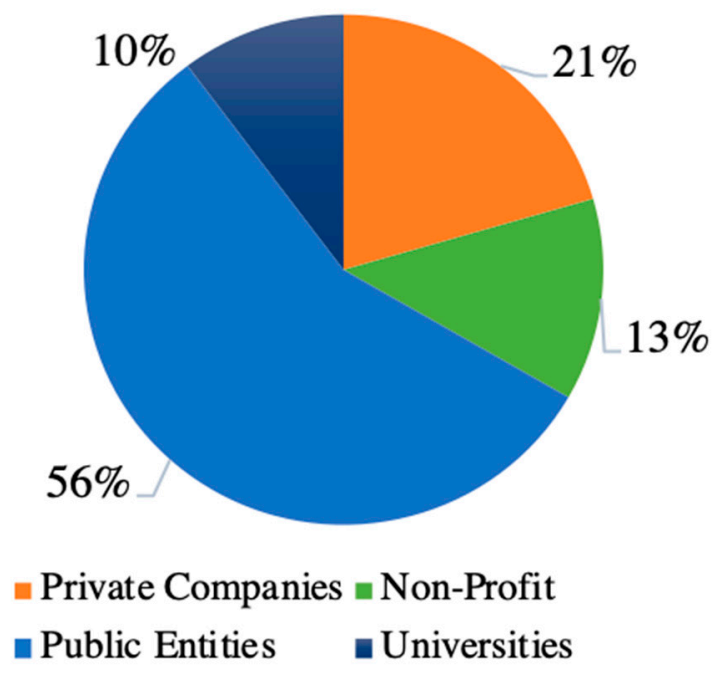

Figure 3. Share of organizations by type.

To have such a wide base of public organizations (many entirely devoted to environmental protection or to the development and protection of public services), international NGOs, and groups of organized civil society is expected to enhance the representation of the interests of those individuals who are further from the decision-making process [4]. These include around nine million beneficiary citizens of the greater area of Rio de Janeiro as well as the local companies and rural producers that are dependent on the preservation of the basin's resources. The theoretical argument for large public participation in environmental management is enhanced by the public-good nature of the resources. In this context, private companies often fail to quantify the social costs of externalities given by pollution or, as in this case, soil degradation, thus prompting government intervention [44]. The presence of many local public institutions is argued to bring positive impacts to the dynamics of community representation, helping to develop active citizenship in the region [7]. This result also demonstrates that the informants believe that agricultural activity is strongly directed by the public sector.

Among the 22 public institutions present in the list, ten operate at the local level. These are secretaries, municipalities, or organizations operating in the municipalities closest to the basin, mostly Rio Claro and Piraí. Seven other institutions operate at the state level of Rio de Janeiro, representing the population and the economy of the state, all of which rely on the basin's resources. Two organizations, namely Ceivap and Comite Guandu, are state agencies operating in the management of the basin. Local governments is called on to bring the needs of the community closer to the decision-making process and pushed to assume the role of representing what Duran and Thoenig [44] define as "local public action." Furthermore, the commixture of public and private entities is expected to facilitate the dialogue between them.

Not only is one of the aims of the Projeto Nexus project to create a learning platform to be used in distance learning courses, but the participative approach also carries an instructive value in its attempt to inform the community about both the nexus framework and the threats and opportunities that their resources are facing. In this way, a sense of ownership and active citizenship reinforcing the protection of the area is created.

Lastly, Figure 4 shows the share of expertise in each Nexus sector as represented by each organizational type, drawing on data in Table 2. From this figure, it is possible to understand how 
attention to each respective nexus sector is distributed among stakeholders of the same organization type. We see that all the groups (public, private companies, and private nonprofit organizations) show more concern for the water component. This is justified by the fact that water is the first resource used to supplement the production of both food and energy, whose preservation is, therefore, paramount for the existence of the other sectors.

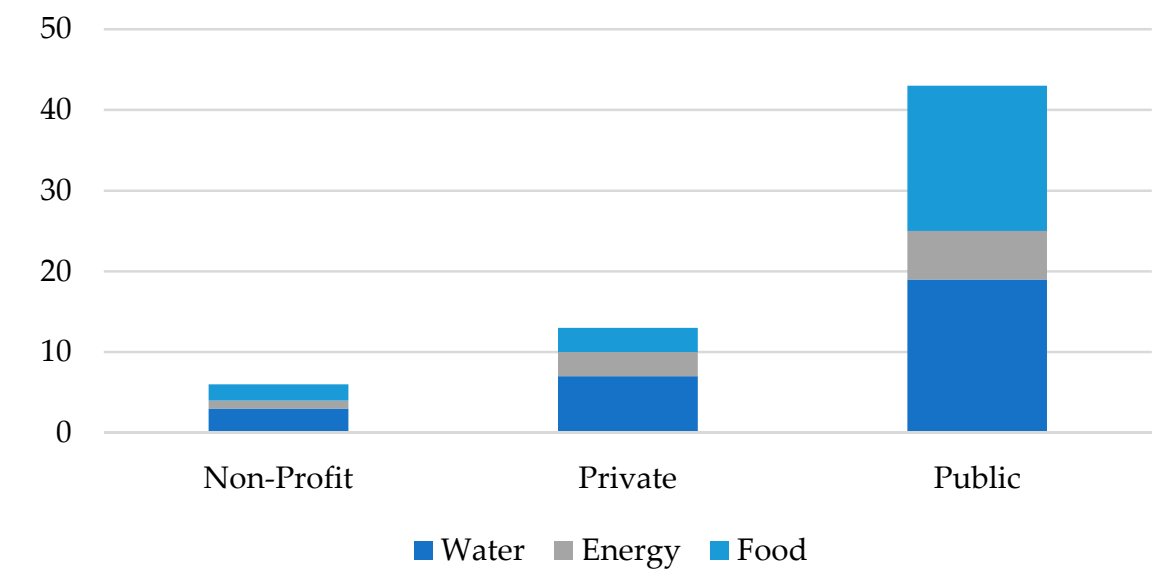

Figure 4. Visual representation of Nexus sectors of interest for stakeholders as a percentage of the type of organization. The vertical axis indicates the number of stakeholders. Universities are not included.

\subsubsection{Threats among Stakeholders}

Lastly, our informants were asked to point out stakeholders who are currently being neglected, thus potentially undermining project developments due to conflicting interests. Only one stakeholder proposed that there may be some counter-pressures from Light and CEDAE, the two organizations with the greatest local presence.

Other interviewees clearly stated that there should be no stakeholder who might be against the objectives of the project, unless communication problems between stakeholders arise later. These problems may be due to different understanding of the issues affecting the area being evaluated in Projeto Nexus and, therefore, an uneven understanding of the potential return that the proposed responses could bring to the company or the environment.

Specifically, one of the informants hypothesized that such a problem may occur with Light and CEDAE, by stating the following:

"I do not see any entities that could directly harm the project. Perhaps the non-participation of some institutions will reduce the scope of the project, for example, the companies of energy [Light, Cemig] or water and sanitation [Cedae], which do not realize the importance of collaborating with the project and the return that this would mean to the companies themselves."

Another informant expressed similar concerns, suggesting that many involves private companies and rural producers in the area may oppose the project, not joining it because they feel excluded or because they are not informed about the scenario and the possible outcomes of the project. In particular, the informant said:

"Rural producers themselves may not be interested in joining Projeto Nexus if they are not well informed and aware of the project's objectives and the benefits they can have from adopting good agricultural and environmental practices."

Lastly, two informants highlighted the relevance of good communication and cooperation between the public and the private sectors, as well as the social and environmental responsibilities that they hold. They stated, respectively, that the stakeholders who might undermine the outcome of the projects are: 
"Both public and private entities, as long as they are not involved in related actions."

Also:

"Public and private, depending on the lack of socio-environmental responsibility".

These concerns are in line with those aforementioned regarding the relevance of creating a solid, common understanding of the scenario, the WEF Nexus, the issues, and the policy responses [9]. Furthermore, to keep informed and to give a voice to local producers who may generally be excluded from the decision-making process, as they have no direct influence, it is argued that if stakeholders perceive that their interests and necessities have not been taken into consideration, they can nourish a sense of hostility against the project and obstruct its implementation.

\section{Conclusions}

Our study is built on and contributes to the literature that implements nexus assessment through a stakeholder analysis $[13,19]$ to tackle challenges that may arise throughout its implementation. These are the creation of a common understanding of the natural resource scenario, as well as the institutional framework of entities governing the resources or depending on their conservation. The incomplete communication flow among stakeholders may harm the decision-making process and hinder effective policy implementation causing science-to-policy gaps $[15,18,19]$. We encourage the inclusion of a diverse set of stakeholders in the decision-making process for land use management due to its normative and instrumental benefits [9]. For this purpose, we test and verify the feasibility of stakeholder analysis for the region and the multi-level evaluation process embedded in rural landscape planning and WEF nexus governance. Snowball sampling has proved to be an effective methodology to gather a pool of diverse stakeholders pertaining to different organizational categories, providing us with a more complete framework of actors and institutions from the region.

As a secondary result, we claim that the participation of different public entities in the decision making process will result in a clearer representation of societal needs.

The stakeholder analysis itself is characterized by several specific properties that make it a suitable tool for the implementation of the nexus, such as being an inherently participative process that helps the co-production of knowledge and the mutual recognition of stakeholders [4,9], creating an arena for experts and stakeholders to find the best policy responses.

This research is also a case study of the application of the nexus assessment in the framework of a participatory evaluation project in land use management in the Atlantic Forest biome, that seeks to evaluate the impact of rural practices in the WEF nexus.

The need for stakeholder analysis originates from two aspects of the research. First is the interdisciplinarity of the nexus assessment, which calls for the active co-creation of knowledge nurtured by the diverse background of a broad range of stakeholders [3,19]. Secondly, the participatory approach used to consolidate the evaluation and decision-making processes calls for the active participation and engagement of a wide spectrum of stakeholders [4,32], who are not only those actors who can affect change, but also those affected by it [5]. Thus, there is a need to represent a wide range of societal needs through the identification and categorization of the actors who define the scenario. In turn, this has the benefit of enhancing the democratic representativeness $[6,32]$ and the civic participation of the local community [7].

Based on the methodology of Reeds et al. [9], we build a stakeholder analysis that aligns with the aim of Projeto Nexus, located in the Atlantic Forest Area of the Reservoir of Ribeirão das Lajes, Brazil, and that provides us with a good understanding of the actors who define the scenario and who should be considered in the decision-making process. The research carried out produced information obtained from the expert's responses that is functional with respect to the stakeholders' dialogue. We processed the results to address the first two aims of the stakeholder analysis, namely identification and categorization. This contributes to the research, providing us with three main results: (i) Our informants identify 32 organizations that, together with the previous partners of the project, make up 
a pool of 39 stakeholders. The informants consider that these stakeholders should take part in the decision-making process either due to their dependency on the resources or the influence that they have in the area. (ii) The categorization of these stakeholders by organization type and main Nexus sector of interest reveals a majority of public institutions, supporting the general view that agricultural activity is strongly directed by the public sector. This result is supported by the need to represent a wide range of societal needs that are related to security of the WEF nexus, the primary aim of Projeto Nexus. Furthermore, this result is also set to improve the communication between the private and public sectors, in a scenario that has seen the dominating presence of one main company, the owner of the land in the area, for more than 100 years. (iii) No entity has been identified as a stakeholder that could harm the development of the project. Instead, the main factor pointed out by the informants as a possible threat to the development of the project is the lack of communication across sectors and with small, local companies and rural producers.

Author Contributions: G.M. and A.P.D.T., contributed to the conception and design of the study. G.M. wrote the first draft of the manuscript with support from A.P.D.T.; M.B. and S.S. provided critical feedback that helped shape the research. All authors have read and agreed to the published version of the manuscript.

Funding: This research is funded by the National Council for Scientific and Technological Development (CNPq)-441313/2017-5.

Conflicts of Interest: The authors declare no conflict of interest.

\section{References}

1. Bhaduri, A.; Ringler, C.; Dombrowski, I.; Mohtar, R.; Scheumann, W. Sustainability in the water-energy-food nexus. Water Int. 2015, 40, 723-732. [CrossRef]

2. Flammini, A.; Puri, M.; Pluschke, L.; Dubois, O. Walking the Nexus Talk: Assessing the Water-Energy-Food Nexus in the Context of the Sustainable Energy for All Initiative; Climare, Energy and Tenure Division (NRC), Food and Agriculture Organization pf the United Nations (FAO): Rome, Italy, 2014.

3. Hoolohan, C. Engaging stakeholders in research to address water-energy-food (WEF) Nexus challenges. Sustain. Sci. 2018, 1415-1426. [CrossRef]

4. Vogler, D.; Macey, S.; Sigouin, A. Stakeholder Analysis in Environmental and Conservation Planning. Lessons Conserv. 2017, 7, 5-16.

5. Freeman, R. Strategic Management: A Stakeholder Approach; Pitman: Boston, MA, USA, 1984.

6. Reed, M. Stakeholder participation for environmental management: A literature review. Biol. Conserv. 2008, 141, 2417-2431. [CrossRef]

7. Milani, C. O princípio da participação social na gestão de políticas públicas locais: Uma análise de experiências latino-americanas e européias. Rivista de Administração Publica 2008, 42, 551-579. [CrossRef]

8. Mohtar, R.; Daher, B. Water-Energy-Food nexus Framework for facilitating multi-stakeholder dialogue. Water Int. 2016, 41, 655-661. [CrossRef]

9. Reed, M. Who's in and why? A typology of stakeholder analysis methods for natural resource management. J. Environ. Manag. 2009, 90, 1933-1949. [CrossRef] [PubMed]

10. IPCC. Climate Change 2013: The Physical Science Basis. Contribution of Working Group I to the Fifth Assessment Report of the Intergovernmental Panel on Climate Change; Stocker, T.F., Qin, D., Plattner, G.-K., Tignor, M., Allen, S.K., Boschung, J., Nauels, A., Xia, Y., Bex, V., Midgley, P.M., Eds.; Cambridge University Press: Cambridge, UK; New York, NY, USA, 2013; p. 1535.

11. Mercure, J.-F.; Paim, M.A.; Bocquillon, P.; Lindner, S.; Salas, P.; Martinelli, P.; Berchin, I.I.; de Andrade Guerra, J.B.S.O.; Derani, C.; de Albuquerque Junior, C.L.; et al. System complexity and policy integration challenges: The Brazilian Energy-Water-Food Nexus. Renew. Sustain. Energy Rev. 2019, 105, 230-243. [CrossRef]

12. Kurian, M.; Ardakanian, R. Governing the Nexus. Water, Soil and Waste Resources Considering Global Change; Springer: Berlin, Germany, 2015.

13. White, D. Stakeholder Analysis for the Food-Energy-Water nexus in Phoenix, Arizona: Implications for nexus Governance. Sustainability 2017, 2204. [CrossRef] 
14. Biggs, M. Sustainable development and the water-energy-food Nexus: A perspective on livelihoods. Environ. Sci. Policy 2015, 54, 389-397. [CrossRef]

15. Hagemann, N.; Kirschke, S. Key Issues of Interdisciplinary NEXUS Governance Analyses: Lessons Learned from Research on Integrated Water Resources Management. Resources 2017, 6, 9. [CrossRef]

16. Scott, C.A.; Kurian, M.; Wescoat, J.L. The Water-Energy-Food Nexus: Enhancing Adaptive Capacity to Complex Global Challenges. In Governing the Nexus; Kurian, M., Ardakanian, R., Eds.; Springer International Publishing: Cham, Switzerland, 2015; pp. 15-38. ISBN 978-3-319-05746-0.

17. Ringler, C.; Bhaduri, A.; Lawford, R. The Nexus across water, energy, land and food (WELF): Potential for improved resource use efficiency? Curr. Opin. Environ. Sustain. 2013, 5, 617-624. [CrossRef]

18. Rasul, G. Managing the food, water, and energy Nexus for achieving theSustainable Development Goals in South Asia. Environ. Dev. 2016, 18, 14-25. [CrossRef]

19. Howarth, C.; Monasterolo, I. Understanding barriers to decision making in the UK energy-food-water Nexus: The added value of interdisciplinary approaches. Environ. Sci. Policy 2016, 53-60. [CrossRef]

20. Endo, A.; Tsurita, I.; Burnett, K.; Orencio, P.M. A review of the current state of research on the water, energy, and food nexus. J. Hydrol. Reg. Stud. 2017, 11, 20-30. [CrossRef]

21. Cairns, R.; Krzywoszynska, A. Anatomy of a buzzword: The emergence of 'the water-energy-food Nexus' in UK natural resource debates. Environ. Sci. Policy 2016, 64, 164-170. [CrossRef]

22. The regional environmental Centre for Central Asia (CAREC). Stakeholder Analysis Report. In Central Asia Nexus Dialogue Project: Fostering Water, Energy, and Food SecurityNexus Dialogue and Multi-Sector Investment; Springer: Almaty, Kazakhstan, 2017.

23. Atkinson, R.; Flint, J. Accessing Hidden and Hard-to-Reach Populations: Snowball Research Strategies. Soc. Res. Update 2001, 33, 1-4.

24. Sadler, G.R.; Lee, H.-C.; Lim, R.S.-H.; Fullerton, J. Recruitment of hard-to-reach population subgroups via adaptations of the snowball sampling strategy: Hard-to-reach populations. Nurs. Health Sci. 2010, 12, 369-374. [CrossRef]

25. Kapoor, I. Towards participatory environmental management? J. Environ. Manag. 2001, 63, $269-279$. [CrossRef]

26. Chen, H.; Rossi, P. The multi-goal, theory-driven approach to evaluation: A model linking basic an applied social science. Soc. Forces 1980, 59, 106-122. [CrossRef]

27. Liu, J. nexus approaches to global sustainable development. Nat. Sustain. 2018, 1, 466-476. [CrossRef]

28. Jones, N. Evaluating Participatory Modeling: Developing a Framework for Cross-Case Analysis. Environ. Manag. 2009, 44, 1180. [CrossRef] [PubMed]

29. Walker, B.; Carpenter, S.R.; Anderies, J.M.; Abel, N.; Cumming, G.; Janssen, M.A.; Lebel, L.; Norberg, J.; Peterson, G.D.; Pritchard, R. Resilience Management in Social-ecological Systems: A Working Hypothesis for a Participatory Approach. Conserv. Ecol. 2002, 6, art14. [CrossRef]

30. Siebenhuner, V.; Barth, V. The role of computer modeling in participatory integrated assessments. Environ. Impact Assess. Rev. 2005, 367-389. [CrossRef]

31. Blackstock, K.; Kelly, G.; Horsey, B. Developing and applying a framework to evaluate participatory research for sustainability. Ecol. Econ. 2007, 60, 726-742. [CrossRef]

32. Sterling, E.J. Assessing the evidence for stakeholder engagement in biodiversity conservation. Biol. Conserv. 2017, 159-171. [CrossRef]

33. Scheffer, M.; Bascompte, J.; Bjordam, T.K.; Carpenter, S.R.; Clarke, L.B.; Folke, C.; Marquet, P.; Mazzeo, N.; Meerhoff, M.; Sala, O.; et al. Dual thinking for scientists. Ecol. Soc. 2015, 20. [CrossRef]

34. Barbosa, L.; Abrantes, E.; De Seixas Filho, J. O estado da arte da represa Ribeirão das Lajes. Semioses 2016, 10, 71-78. [CrossRef]

35. Rocha, C. The remnants of restinga habitats in the brazilian Atlantic Forest of Rio de Janeiro state, Brazil: Habitat loss and risk of disappearance. Braz. J. Biol. 2007, 67, 263-273. [CrossRef]

36. Morales, A. Drought in US and Brazil linked to hottest year ever. Bloomberg New Energy Financ. $2014,3,20$.

37. Semertzidis, T.; Spataru, C.; Bleischwitz, R. The Nexus: Estimation of Water Consumption for Hydropower in Brazil. J. Sustain. Dev. Energy Water Environ. Syst. 2019, 7, 122-138. [CrossRef]

38. Vaz, V. A Represa de Ribeirão das Lajes e os efeitos sócio espaciais no planalto da serra do mar no sul do estado do Rio de Janeiro. In Simpósio Inter-Nacional Glolización, Innovación y Construcción de Redes Técnicas Urbanas em América y Europa 1890-1930; Universidade de: Barcelona, Spain, 2012. 
39. Serqueira, C.d.M. A História Submersa da Represa de Lajes. Available online: http://www.aseac.com.br/ ribeirao.htm (accessed on 11 July 2020).

40. König, H.J. Regional impact assessment of land use scenarios in developing countries using the FoPIA approach: Findings from five case studies. J. Environ. Manag. 2013, 127, 56-64. [CrossRef] [PubMed]

41. Costa Coutinho, H. Participatory Sustainability Assessment for Sugarcane Expansion in Goiás, Brazil. Sustainability 2017, 9, 1573. [CrossRef]

42. Hare, M.; Pahl-Wostl, C. Stakeholder Categorisation in Participatory Integrated Assessment Processes. Integr. Assess. 2002, 3, 50-62. [CrossRef]

43. Stavins, R. Introduction to the Political Economy of Environmental Regulation (January 2004). KSG Working Paper n RWP04-004. Available online: https://papers.ssrn.com/sol3/papers.cfm?abstract_id=500143 (accessed on 11 July 2020).

44. Duran, P.; Thoenig, J. L'Etat et la gestion publique territoriale. Rev. Française Sci. Polit. 1996, 46, 580-623.

(C) 2020 by the authors. Licensee MDPI, Basel, Switzerland. This article is an open access article distributed under the terms and conditions of the Creative Commons Attribution (CC BY) license (http://creativecommons.org/licenses/by/4.0/). 